\title{
Association of serum thyrotropin levels with coronary artery disease documented by quantitative coronary angiography: a transversal study
}

Pedro D. Ortolani Jr. ', João H. Romaldini', Ricardo A. Guerra', Evandro S. Portes', George C. X. Meireles' ${ }^{2}$, João Pimenta ${ }^{2}$

${ }^{1}$ Serviço de Endocrinologia, Hospital do Servidor Público Estadual de São Paulo, Instituto de Assistência Médica ao Servidor Público Estadual (HSPEIAMSPE), São Paulo, SP, Brasil

${ }^{2}$ Serviço de Cardiologia, Hospital do Servidor Público Estadual de São Paulo, Instituto de Assistência Médica ao Servidor Público Estadual (HSPE-IAMSPE), São Paulo, SP, Brasil

Correspondence to:

Pedro Dirceu Ortolani Júnior Serviço de Endocrinologia,

Hospital do Servidor Público Estadual

Rua Pedro de Toledo, 1.800

04039-000 - São Paulo, SP, Brasil

pdojr@terra.com.br

Received on Oct/3/2017

Accepted on Mar/10/2018

DOI: $10.20945 / 2359-3997000000054$

\begin{abstract}
Objective: The association between coronary artery disease (CAD) and thyroid function remains controversial. We evaluated the thyroid function and graduated well-defined CAD as confirmed by quantitative coronary angiography (CA). Subjects and methods: We evaluated the serum TSH, free thyroxine, free triiodothyronine and thyroid antibody levels in 300 consecutive patients (age $61.6 \pm$ 9.9 years and $54 \%$ were male) undergoing CAD diagnosis as confirmed by CA. Plaques with $\geq 50 \%$ stenosis being indicative of obstructive $C A D$, and patients were divided into groups according to main epicardial coronary arteries with plaques $(0,1,2,3)$. Lipid profiles and a homeostasis model assessment (HOMA-IR) were determined. Results: Serum median (25\% and $75 \%$ percentile) TSH levels in patients with group 2 and $3(2.25 ; 1.66-3.12 \mathrm{mU} / \mathrm{L}$ and $4.99 ; 4.38-23.60 \mathrm{mU} / \mathrm{L}$, respectively) had significantly higher TSH concentrations $(p<0.0001)$ than the group $0(1.82 ; 1.35-2.51 \mathrm{mU} / \mathrm{L})$. Furthermore, patients of group 3 had higher TSH concentration $(p<0.0001)$ than those of group 1 (1.60; 0.89-2.68 $\mathrm{mU} / \mathrm{L})$. Group 3 were older $(64 \pm 8.5 \mathrm{vs} .59 \pm 9.5, \mathrm{p}=0.001)$, had more patients with dyslipidemia ( $84 \%$ versus $58 \%, p<0.001)$, male $(54 \%$ versus $44 \%, p=0.01)$, hypertension $(100 \%$ versus $86 \%, p<0.001)$, and smoking $(61 \%$ versus $33 \%, p<0.001)$ than group 0 . Multivariate stepwise logistic analysis showedTSH, age, HbA1c, and HOMA-IR were the CAD associated variables. Conclusions: In this cohort, elevated TSH levels in the high normal range or above are associated with the presence and severity of CAD besides may represent a weak CAD risk factor. Arch Endocrinol Metab. 2018;62(4):410-5

\section{Keywords}

TSH; coronary artery disease; coronary angiography
\end{abstract}

\section{INTRODUCTION}

$\mathrm{H}$ ypothyroidism is typically associated with elevated endothelial dysfunction and increased all-cause mortality in addition to cardiac death and/or hospitalization (1-3). Several studies have shown that coronary atherosclerosis in subjects with hypothyroidism is more frequent and severe than in normal subjects (4). In addition, there is some evidence that an elevated serum TSH in association with serum thyroid peroxidase antibody (TPOAb) may alter the traditional risk factors for coronary arterial disease (CAD), perhaps because of the accumulation of circulating levels of atherogenic total cholesterol (TC) and low-density lipoprotein (LDL) cholesterol particles (5-9). Consequently, the relation between thyroid dysfunction and CAD remains questionable (10), however, some authors have found a positive correlation between serum TSH levels and the presence and severity of coronary stenosis (6,11-14); other authors have found no correlation between these two parameters $(15,16)$. In contrast, Coceani and cols. observed a negative correlation with serum FT3 (but not with FT4 levels) and CAD (17). On the other hand, Miura and cols. found that independent of conventional cardiovascular risk factors, thyroid hormones (FT3 and FT4) inversely correlated with coronary artery disease, especially men $(18,19)$. A meta-analysis demonstrated that high TSH values were associated with cardiovascular risk in patients $<65$ years old, whereas another study reported that in patients $>85$ years old, increased serum TSH values played a protective role against the development of CAD $(20,21)$. Furthermore, it remains to be determined whether serum TSH, FT4, FT3, TPOAb or thyroglobulin antibody ( $\mathrm{TgAb}$ ) levels are associated with CAD development. The aim of this 
study was to yield greater insight into the assessment of thyroid function parameters and lipid concentrations in consecutive patients undergoing quantitative coronary angiography (CA).

\section{SUBJECTS AND METHODS}

\section{Patients}

Data were obtained from 343 consecutive patients in the Cardiology Outpatient Unit, Hospital do Servidor Público Estadual de São Paulo, Instituto de Assistência Médica ao Servidor Público Estadual (HSPE-IAMSPE) in Brazil that were referred for CA because of signs or symptoms relevant to CAD. All of the patients satisfied two inclusion criteria: 1) characteristic signs of myocardial ischemia on non-invasive tests and 2) clinical recommendation for further assessment. We used a questionnaire to assess classical risk factors for CAD such as diabetes, hypertension, dyslipidemia, smoking, and a family history of premature CAD (defined as $\leq 55$ years old for males and $\leq 65$ years old for females). Patients were excluded in cases with a history of thyroid diseases, documented $\mathrm{CAD}$, acute $\mathrm{CAD}$, or ischemic equivalent (such as dyspnea, sickness, confusion, stroke or pulmonary edema, compatible electrocardiographic signs, or increased creatine kinase-MB [CK-MB)] and/or troponin levels) (22). We excluded patients who were using amiodarone, levothyroxine, or antithyroid drugs (such as methimazole or propylthiouracil). Forty-three patients were excluded, and the remaining 300 patients were enrolled in the study. All of the patients included in the study received an explanation of the purpose of the study and signed a consent form. This work was submitted to the Research Ethics Committee of IAMSPE and approved without restrictions.

\section{Assessment of CA}

All of the patients were assessed via CA and further analyzed by an independent observer who was not involved in patients medical care. The quantification of the CA was performed manually. The CA was carried out using a femoral approach and a 6- or 7-F guiding catheter. Right and left CAs were performed in multiple projections using standard techniques and used to evaluate coronary artery stenosis (23). CAD was defined according to CA results, and significant stenosis was defined as a decrease in internal diameter of $\geq 50 \%$, which could affect one or more of the main epicardial coronary arteries (such as the right coronary, left anterior descending, or circumflex arteries) and classified as group 1, 2, or 3 according the number of vessels with significant stenosis (24). Patients were classified as group 0 if they had no CAD or when the main epicardial coronary arteries were $<50 \%$ of the internal diameter.

\section{Biochemical analysis}

Blood samples were drawn after overnight fasting prior to the CA. For the hormone assessment, patient samples were stored at $-20^{\circ} \mathrm{C}$ until the time of measurement and analyzed in our laboratory. Blood glucose levels were estimated using the glucose oxidase method. Hemoglobin Alc (HbAlc), CK-MB, and cardiac troponin levels were determined by HPLC, electrochemiluminescent immunoassay, and twosite enzyme-linked immunosorbent assay methods, respectively. Serum TC, triglycerides (TG), and highdensity lipoprotein (HDL) cholesterol levels were measured enzymatically. To determine LDL-cholesterol levels, the formula from Friedewald and cols. was used (25). Serum creatinine level was analyzed using a colorimetric method, and hepatic enzyme levels were determined enzymatically.

\section{Hormonal analysis}

Serum TSH, FT4, and FT3 levels were measured using direct chemiluminescent technology (Advia Centaur XP Immunoassay System; Siemens Healthcare Diagnostics, Deerfield, IL, USA) using reference values ranging from 0.3-4.1 mU/L for TSH, 0.8-2.0 ng/dL for FT4, and $1.6-4.1 \mathrm{pg} / \mathrm{mL}$ for FT3. The mean interassay CV was 3.1, 11.0, and $8.9 \%$ for TSH, FT4, and FT3, respectively. TPOAb and $\mathrm{TgAb}$ serum concentrations were determined via a chemiluminescent immunometric assay (Diagnostic Products Co., Los Angeles, CA, USA), and values > $35 \mathrm{IU} / \mathrm{L}$ were considered to be positive. Serum insulin was analyzed using a chemiluminescent immunometric assay (Diagnostic Products Co.). The homeostasis model assessment of insulin resistance (HOMA-IR) index was determined using serum glucose and insulin values: fasting insulin $(\mathrm{mU} / \mathrm{mL}) \times$ fasting blood glucose $(\mathrm{mg} / \mathrm{dL}) / 405$. Body mass index (BMI) was expressed as $\mathrm{kg} / \mathrm{m}^{2}$.

\section{Statistical analysis}

Differences between the groups were verified by the Kruskal-Wallis in conjunction with the Dunn's multiple 
comparison tests, and thereafter they were compared two-by-two using the Mann-Whitney rank test. Chisquare or Fischer's exact tests were used to compare proportions Univariate and multivariate analyses with multinomial logistic regression analysis were used to evaluate the risks associated with CA results. For univariate analysis a less-restrictive alpha level with a 0.1 was used, and so a broad range of variables are considered for inclusion in the model. Thereafter, a backward stepwise multiple regression analysis was employed using $\mathrm{CAD}$ as dependent variable. A beta coefficient, standard error of beta coefficient (SE), and 95\% confidence interval were obtained. SAS software version 9.4 (SAS Institute Inc., Cary, NC) was used for all analyses.

\section{RESULTS}

Characteristics of patients that were analyzed and patient demographics are reported in Table 1. All enrolled patients underwent all tests according to schedule. The mean age was of $61.6 \pm 9.9,>90 \%$ of patients had hypertension, $72 \%$ had dyslipidemia, and almost half of them were smokers. Mean serum TSH levels were $3.0 \pm 2.7(\mathrm{SD}) \mathrm{mU} / \mathrm{L}$, and $11 \%$ of patients had positive thyroid antibodies. Significant stenosis ( $\geq 50 \%$ in one or more main epicardial vessels)

Table 1. Baseline characteristics of 300 patients participants in the study

\begin{tabular}{lc}
\hline Variables & Number (\%) or mean \pm SD \\
\hline Age, years & $61.6 \pm 9.9$ \\
Male & $162(54)$ \\
Diabetes mellitus & $107(36)$ \\
Hypertension & $275(92)$ \\
Smoking & $147(49)$ \\
Family history of CADa & $70(23)$ \\
Dyslipidemia & $215(72)$ \\
BMl, kg/m² & $28.2 \pm 4.5$ \\
Total cholesterolemia, mg/dL & $178.7 \pm 37.9$ \\
HDL-cholesterolemia, mg/dL & $49.1 \pm 14.1$ \\
Trygliceridemia, mg/dL & $134 \pm 73.1$ \\
HbA1c, \% & $6.3 \pm 1.4$ \\
LDL-cholesterolemia, mg/dL & $101 \pm 31.9$ \\
Thyroid antibodies & $34(11)$ \\
TSH, mU/L & $3.0 \pm 2.7$ \\
FT4, ng/dL & $1.2 \pm 0.4$ \\
FT3, ng/dL & $2.9 \pm 0.6$ \\
\hline
\end{tabular}

SD: standard deviation.

${ }^{a}$ CAD coronary artery disease. ${ }^{b}$ Presence of serum thyroglobulin antibody and thyroid peroxidase antibody. was observed in $62 \%$ (185) of patients. Arterial vessel stenosis was observed in 60 patients (group 1), 64 patients had two stenosed vessels (group 2), and 61 patients had three stenosed vessels (group 3). Figure 1 shows the results of serum TSH concentration in patients undergoing CA examination. Serum median and a $25 \%$ and $75 \%$ percentile of TSH levels in patients of group $2(2.25 ; 1.66-3.12 \mathrm{mU} / \mathrm{L})$ and group 3 (4.99; 4.38-23.60 mU/L) had significantly higher TSH concentrations $(\mathrm{p}<0.0001)$ than the group 0 (1.82; 1.35-2.51 mU/L). Furthermore, patients of group 3 had higher TSH concentration $(\mathrm{p}<0.0001)$ than those of groupl $(1.60 ; 0.89-2.68 \mathrm{mU} / \mathrm{L})$ as shown Figure 1. Moreover, group 3 had significant more patients with dyslipidemia, hypertension and smoking than group 0 patients. In group 3, the mean HbAlc levels were higher than other groups, and were older as shown Table 2 . The group 2 had similar figure; had more male, smoking and diabetes patients as well as high HbAlc level, and older than group 0. Univariate logistical regression analysis revealed that male sex, diabetes mellitus, hypertension, dyslipidemia, smoking, older age and TSH were significant risk factors for CAD (Table 3). Thereafter, as shown in Table 4, the stepwise backward multiple regression model of CAD identified TSH, older age, HbAlc, and HOMA-IR as CAD risk factors $\left(\mathrm{R}^{2}=0.377\right.$; Adjusted $\mathrm{R}^{2}=0.369 ; \mathrm{SE}=0.922 \mathrm{~F}$ $=42.526 ; \mathrm{p}$-value $=0.0001)$.

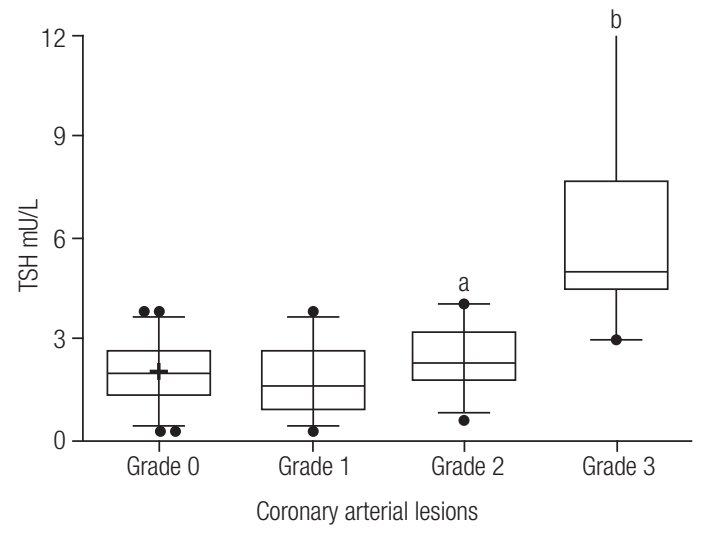

Figure 1. Box-and-whisker plot of the differences in the serum TSH median observed between patients undergoing the coronary angiography. Group 0; absence of coronary artery disease (when the vessels were $<50 \%$ of the internal diameter). Group 1, 2, and 3; according to the number of vessels with significant stenosis. The median is the center line, the ends of the box represent the $25^{\text {th }}$ and $75^{\text {th }}$ percentiles, and the ends of the lines extend to the $2.5^{\text {th }}$ and $97.5^{\text {th }}$ percentiles.

Differences between the groups were analyzed by the Kruskal-Wallis test. $(H=203.5 ; p<0.0001)$.

${ }^{a} p<0.02$ vs. group $0 ;{ }^{b} p<0.0001$ vs. group 0,1 and 2 (Verified by the Mann-Whitney test was used). 
Table 2. Characteristics of patients according to the coronary artery angiography

\begin{tabular}{|c|c|c|c|c|c|c|}
\hline Variables & Group $0^{\mathrm{a}}$ & Group 1 & Group 2 & $\mathbf{p}^{\mathrm{b}}$ & Group 3 & $\mathbf{p}^{c}$ \\
\hline number & 115 & 60 & 64 & & 61 & \\
\hline Age, mean \pm SD & $59 \pm 9.5$ & $61.4 \pm 10.1$ & $63.8 \pm 10.6$ & 0.002 & $64.7 \pm 8.5$ & 0.001 \\
\hline Male, n (\%) & $51(44)$ & $31(52)$ & $36(56)$ & 0.015 & $33(54)$ & 0.01 \\
\hline Diabetes mellitus, $n(\%)$ & $31(27)$ & $19(32)$ & $25(39)$ & 0.0001 & $33(54)$ & 0.107 \\
\hline Hypertension, n (\%) & $99(86)$ & $55(92)$ & $60(94)$ & 0.142 & $61(100)$ & 0.0001 \\
\hline Smoking, n (\%) & $38(33)$ & $32(53)$ & $39(65)$ & 0.001 & $37(61)$ & 0.0007 \\
\hline Familiar history of CAD & $24(21)$ & $17(28)$ & $13(20)$ & 1.001 & $17(28)$ & 0.259 \\
\hline Dyslipidemia, n (\%) & $67(58)$ & $44(73)$ & $54(84)$ & 0.142 & $51(84)$ & 0.0001 \\
\hline $\mathrm{BMI}, \mathrm{Kg} / \mathrm{m}^{2}$, mean $\pm \mathrm{SD}$ & $29.0 \pm 4.9$ & $27.2 \pm 4.0$ & $27.5 \pm 4.3$ & 0.059 & $28.3 \pm 3.9$ & 0.097 \\
\hline Total cholesterolemia, mg/dL & $185.2 \pm 35.2$ & $174.7 \pm 39.1$ & $174.4 \pm 39.2$ & 0.610 & $175.3 \pm 38.9$ & 0.088 \\
\hline HDL-cholesterolemia, mg/dL & $50.3 \pm 11.7$ & $49.7 \pm 12.4$ & $48.0 \pm 15.7$ & 0.210 & $47.4 \pm 12.7$ & 0.130 \\
\hline Trygliceridemia, mg/dL & $131 \pm 70.6$ & $136.3 \pm 83.2$ & $133.3 \pm 65.4$ & 0.450 & $137.6 \pm 76.2$ & 0.213 \\
\hline LDL-cholesterolemia, mg/dL & $108 \pm 32.5$ & $97.7 \pm 33.7$ & $99.5 \pm 29.8$ & 0.750 & $100.5 \pm 33.1$ & 0.923 \\
\hline $\mathrm{HbA1c}, \%$, mean $\pm \mathrm{SD}$ & $6.0 \pm 1.2$ & $6.1 \pm 1.3$ & $6.5 \pm 1.4$ & 0.002 & $6.7 \pm 1.8$ & 0.018 \\
\hline Thyroid antibodies ${ }^{\mathrm{d}}, \mathrm{n}(\%)$ & $12(10)$ & $9(15)$ & $7(10.9)$ & 0.607 & $7(11.4)$ & 0.596 \\
\hline $\mathrm{TSH}, \mathrm{mU} / \mathrm{L}$ & $2.7 \pm 2.1$ & $3.1 \pm 2.6$ & $2.9 \pm 2.1$ & 0.025 & $3.5 \pm 3.8$ & 0.0001 \\
\hline $\mathrm{FT} 4, \mathrm{ng} / \mathrm{dL}$ & $1.1 \pm 0.2$ & $1.1 \pm 0.2$ & $1.2 \pm 0.2$ & 0.139 & $1.1 \pm 0.2$ & 0.758 \\
\hline $\mathrm{FT} 3, \mathrm{ng} / \mathrm{dL}$ & $2.9 \pm 0.5$ & $2.9 \pm 0.6$ & $3.0 \pm 0.5$ & 0.254 & $2.9 \pm 0.5$ & 0.800 \\
\hline
\end{tabular}

SD: standard deviation.

${ }^{a}$ Group was classified as the number of main epicardial vessels with stenosis: Group 0 when vessels without lesion or less than $50 \%$ of the internal diameter, Group 1 when one vessel with lesion equal or more than $50 \%$ of the internal diameter, Group 2 when two vessels with lesion equal or more than $50 \%$ of the internal diameter, Group 3 when three vessels with lesion equal or more than $50 \%$ of the internal diameter.

${ }^{\mathrm{b}} \mathrm{p}$-values significant between patients with Group 0 and Group-2, and no significant with Group 1.

${ }^{c} p$-values significant between patients with Group 0 and Group 3, and no significant with Group 1 and Group 2.

${ }^{d}$ Presence of serum thyroglobulin antibody and thyroid peroxidase antibody Kruskal-Wallis was used $(H=7357.8 ; p<0.00010$. Mann-Whitney test was used for continuous variables between the groups, and the Chi-Square or Fischer's exact test was used for categorical variables.

Table 3. Risk factors associated with coronary arterial disease in patients undergoing coronary angiography by univariate logistic regression analysis

\begin{tabular}{lccc}
\hline Variable & Adjusted odds ratio & 95\% Confidence Interval & p \\
\hline Age, years & 1.05 & $1.02-1.07$ & $<0.01$ \\
Male & 1.93 & $1.27-2.93$ & $<0.01$ \\
Diabetes mellitus & 1.17 & $1.41-3.34$ & $<0.01$ \\
Hypertension & 3.55 & $1.53-8.24$ & $<0.01$ \\
Dyslipidemia & 2.74 & $1.70-4.42$ & $<0.01$ \\
Smoking & 2.35 & $1.54-3.57$ & $<0.01$ \\
HOMA-IR & 1.12 & $1.05-1.20$ & $<0.01$ \\
HbA1c & 1.32 & $1.13-1.54$ & $<0.01$ \\
TSH & 1.07 & $0.99-1.16$ & $=0.08$ \\
\hline
\end{tabular}

Variables such as familiar history of CAD ( $p=0.45)$, BMI $(p=0.21)$, thyroid antibodies $(p=0.78)$, FT4 $(p=0.58)$ and FT3 were not independent risk associated with CAD.

Table 4. Result from stepwise backward regression analysis for presence of coronary arterial disease in patients undergoing coronary angiography

\begin{tabular}{lccccc}
\hline Variables & Coefficients & SE $^{\text {a }}$ & Beta & $\boldsymbol{t}$ & \multicolumn{1}{c}{$\mathbf{p}$} \\
\hline TSH & 0.238544459 & 0.021348719 & 0.52981 & 11.173 & 0.0008 \\
Age & 0.018485266 & 0.005520596 & 0.159255363 & 3.348 & 0.0009 \\
HbA1c & 0.454384746 & 0.121113561 & 0.17814673 & 3.752 & 0.0002 \\
HOMA-IR $^{\text {b }}$ & 0,026698419 & 0.11200489 & 0.112782451 & 2.38 & 0.017 \\
\hline
\end{tabular}

a $S E$, the estimated standard deviation of the error in the model.

${ }^{\mathrm{b}}$ Hemoglobin A1c.

c The homeostasis model assessment of insulin resistance.

Independent variables such as sex $(p=0.31)$, diabetes mellitus $(p=0.27)$, hypertension $(p=0.33)$, dyslipidemia $(0.25)$ and smoking $(p=0.94)$ were not included in the model. 


\section{DISCUSSION}

In this study, we have demonstrated that within our study population, patients with two or three stenosed arterial vessels at the CA assessment had higher serum TSH levels than patients with no stenosis. This study shown that serum TSH level was associated with risk of stenosis, detected during the CA, especially for patients with older age, higher levels of HbAlc and presence of insulin resistance. Serum FT4 or FT3 levels had no effect on the presence of stenosis. Recent meta-analysis provided some important information about the role of thyroid autoimmunity as a possible risk factor for CAD and suggested that biomarkers of thyroid autoimmunity do not add independent prognostic information for CAD outcomes (26). In the present study population, there was no association between significant stenosis seen on the CA and the presence of circulating TPOAb or TgAb. Although our findings using stepwise backward multiple regression model of CAD identified TSH, older age, HbAlc, and HOMA-IR as CAD predictors besides TSH were a weak independent risk factor for CAD. These data are consistent with the hypothesis that serum TSH values, even within in the upper normal reference range, are associated with the presence of stenosis (10). Endothelial dysfunction has been detected in hypothyroid patients, and it has been shown to be associated with low-intensity chronic inflammation, arterial vasodilatation reduction, and the presence of circulating TPOAb or $\operatorname{TgAb}(27,28)$. A limitation of our study was the small number of enrolled patients, which reduced the strength of the reported associations. Furthermore, in an attempt to decrease the influence of acute coronary syndrome, we included only select patients without clinical symptoms of cardiac disease such as chest pain or patients with manifestations of ischemic heart disease. On the other hand, it seems that there was no clear agreement on the association of serum TSH, FT4, and FT3 values with CAD. A multicenter prospective study, including 55,000 patients, revealed that elevated serum TSH levels (particularly levels $>10 \mathrm{mU} / \mathrm{L}$ ) were associated with an increased risk of cardiac events and mortality due to $\mathrm{CAD}$, and Chaker and cols. found that high levels of TSH might increase the risk of stroke in patients $<65$ years old $(29,30)$. Auer and cols. identified a positive correlation between serum TSH levels and the presence and severity of CAD without excluding patients with previous thyroid disease (31). Miura and cols. studied angina patients found in CAD patients lower FT4 and
FT3 levels as compared to patients without coronary stenosis (18). On the contrary, Coceani and cols. assessed approximately 1,000 patients (excluding individuals with acute myocardial infarction) and found no correlation between serum TSH or FT4 levels and $\mathrm{CAD}$ and observed a negative correlation only with serum FT3 levels (17). We did not find any association between serum FT4 and/or FT3 levels and CAD. A direct correlation between TC and LDL cholesterol is well-known, even when serum TSH values are within the reference range, and is usually associated with insulin resistance and in smokers $(8,32)$. Among the many factors associated with CAD, Tatar and cols. reported a direct effect of serum TSH in the upper normal reference range on an increase in arterial stiffness in dialysis patients with euthyroidism (33). On the other hand, serum TSH also increased inflammatory molecules and inhibited nitric oxide production due to oxidative stress as demonstrated by Desideri and cols. and Dardano and cols. $(34,35)$. We were unable to find any evidence for an association between lipid profiles and serum TSH levels, most likely due to the fact that the majority of patients were taking dyslipidemia drugs. Despite the elevated frequency of hypertensive patients in our study population, no association with serum TSH values was noted.

Some paper found results similar to ours study: Yun and cols. used a serum TSH cutoff point of $2.1 \mathrm{mU} / \mathrm{L}$; observed a significant correlation between serum TSH levels and coronary artery lesions in patients with unstable angina (36). Furthermore, using the median serum TSH value $(1.73 \mathrm{mU} / \mathrm{L})$ as a cutoff value, Yang and cols. studied the hospital-based diagnoses of myocardial infarction in 318 patients and found an association between elevated serum TSH values (still within the reference range) and CAD (37). Daswani and cols. found lower FT3 levels in patients with three stenosed vessels were more affected in CAD than in normal patients (38). Finally, the possibility that serum TSH levels is a cardiovascular risk factor has been a subject of debate, and a broad studies are needed for answer this point. In summary, our study suggests that in a population with multiple risk factors for CAD development, there is an association with high serum TSH, even in the upper normal range, with presence and severity of CAD as detected with CA. Furthermore, elevated serum TSH may represent a weak $\mathrm{CAD}$ risk factor.

Disclosure: no potential conflict of interest relevant to this article was reported. 


\section{REFERENCES}

1. Sara JD, Zhang M, Gharib H, Lerman LO, Lerman A. Hypothyroidism is associated with coronary endothelial dysfunction in women. J Am Heart Assoc. 2015;4(8):e002225.

2. Ning N, Gao D, Triggiani V, lacoviello M, Mitchell JE, Ma R, et al. Prognostic role of hypothyroidism in heart failure: A Meta-Analysis. Medicine (Baltimore). 2015;94(30):e1159.

3. Cappola AR, Ladenson PW. Hypothyroidism and atherosclerosis. J Clin Endocrinol Metab. 2003;88(6):2438-44.

4. Cappola AR, Fried LP, Arnold AM, Danese MD, Kuller LH, Burke $\mathrm{GL}$, et al. Thyroid status, cardiovascular risk, and mortality in older adults. JAMA. 2006;295(9):1033-41.

5. Hollowell JG, Staehling NW, Flanders WD, Hannon WH, Gunter EW, Spencer CA, et al. Serum TSH, T(4), and thyroid antibodies in the United States population (1988 to 1994): National Health and Nutrition Examination Survey (NHANES III). J Clin Endocrinol Metab. 2002;87(2):489-99.

6. Walsh JP, Bremner AP, Bulsara MK, O'Leary P, Leedman PJ, Feddema $P$, et al. Subclinical thyroid dysfunction as a risk factor for cardiovascular disease. Arch Intern Med. 2005;165(21):2467-72.

7. Biondi B. Heart failure and thyroid dysfunction. Eur J Endocrinol. 2012;167(5):609-18.

8. Canaris GJ, Manowitz NR, Mayor G, Ridgway EC. The Colorado thyroid prevalence study. Arch Intern Med. 2000;160(4):526-34.

9. Ochs N, Auer R, Bauer DC, Nanchen D, Gussekloo J, Cornuz J, et al. Meta-analysis: subclinical thyroid dysfunction and the risk for coronary heart disease and mortality. Ann Intern Med. 2008; 148(11):832-45.

10. Rodondi N, Bauer DC. Subclinical hypothyroidism and cardiovascular risk: how to end the controversy. J Clin Endocrinol Metab. 2013;98(6):2267-9.

11. Iervasi G, Molinaro S, Landi P, Taddei MC, Galli E, Mariani F, et al. Association between increased mortality and mild thyroid dysfunction in cardiac patients. Arch Intern Med. 2007;167(14):1526-32.

12. Tseng FY, Lin WY, Lin CC, Lee LT, LiTC, Sung PK, et al. Subclinical hypothyroidism is associated with increased risk for allcause and cardiovascular mortality in adults. J Am Coll Cardiol. 2012;60(8):730-7.

13. Hak AE, Pols HA, Visser TJ, Drexhage HA, Hofman A, Witteman JC. Subclinical hypothyroidism is an independent risk factor for atherosclerosis and myocardial infarction in elderly women: the Rotterdam Study. Ann Intern Med. 2000;132(4):270-8.

14. Imaizumi M, Akahoshi M, Ichimaru $S$, Nakashima E, Hida A, Soda M, et al. Risk of ischemic heart disease and all-cause mortality in subclinical hypothyroidism. J Clin Endocrinol Metab. 2004;89(7):3365-70.

15. Rodondi N, Newman AB, Vittinghoff E, de Rekeneire N, Satterfield S, HarrisTB, et al. Subclinical hypothyroidism and the risk of heart failure, other cardiovascular events and death. Arch Intern Med. 2005;165(21):2460-6.

16. Asvold BO, Bjøro T, Platou C, Vatten LJ. Thyroid function and the risk of coronary heart disease: 12-year follow-up of the HUNT Study in Norway. Clin Endocrinol (Oxf). 2012;77(6):911-7.

17. Coceani M, lervasi G, Pingitore A, Carpeggiani C, L'Abbate A. Thyroid hormone and coronary artery disease: from clinical correlations to prognostic implications. Clin Cardiol. 2009;32(7):380-5.

18. Miura S, litaka M, Suzuki S, Fukasawa N, Kitahama S, Kawakami $Y$, et al. Decrease in serum levels of thyroid hormone in patients with coronary heart disease. Endocr J. 1996;43(6):657-63.

19. Kim ES, Shin JA, Shin JY, Lim DJ, Moon SD, Son HY, et al. Association between low serum free thyroxine concentrations and coronary artery calcification in healthy euthyroid subjects. Thyroid. 2012;22(9):870-6.

20. Razvi S, Shakoor A, Vanderpump M, Weaver JU, Pearce SH. The influence of age on the relationship between subclinical hypothy- roidism in ischemic heart disease: a metaanalysis. J Clin Endocrinol Metab. 2008;93(8):2998-3007.

21. Gussekloo J, van Exel E, de Craen AJ, Meinders AE, Frölich M, Westendorp RG. Thyroid status, disability and cognitive function, and survival in old age. JAMA. 2004;292(21):2591-9.

22. Cohn PF, Fox KM, Daly C. Silent ischemia. Circulation. 2003;108(10):1263-77.

23. Williams DO, Gruntzig A, Kent KM et al. Guidelines for the performance of percutaneous transluminal coronary angioplasty. Circulation. 1982;66(4):693-4.

24. Brown BG, Bolson E, Frimer M, Dodge HT. Quantitative coronary arteriography: estimation of dimensions, hemodynamic resistance, and atheroma mass of coronary artery lesions using the arteriogram and digital computation. Circulation. 1977;55(2):329-37.

25. FriedewaldWT, Levy RI, Fredrickson DS. Estimation of the concentration of low-density lipoprotein cholesterol in plasma, without the use of preparative centrifuge. Clin Chem. 1972;18(6):499-502.

26. Collet TH, Bauer DC, Cappola AR, Asvold BO, Weiler S, Vittinghoff E, et al. Thyroid antibody status, subclinical hypothyroidism, and the risk of coronary heart disease: an individual participant data analysis. J Clin Endocrinol Metab. 2014;99(9):3356-62.

27. Taddei S, Caraccio N, Virdis A, Dardano A, Versari D, Ghiadoni L, et al. Low-grade systemic inflammation causes endothelial dysfunction in patients with Hashimoto's thyroiditis. J Clin Endocrinol Metab. 2006;91(12):5076-82.

28. Xiang GD, HeYS, Zhao LS, Hou J,Yue L, Xiang HJ. Impairment of endothelium-dependent arterial dilation in Hashimoto's thyroiditis patients with euthyroidism. Clin Endocrinol (Oxf). 2006;64(6):698-702.

29. Rodondi N, den Elzen WP, Bauer DC, Cappola AR, Razvi S, Walsh JP, et al. Thyroid Studies Collaboration: Subclinical hypothyroidism and the risk of coronary heart disease and mortality. JAMA. 2010;304(12):1365-74.

30. Chaker L, Baumgartner C, den Elzen WP, Collet TH, Ikram MA, Blum MR, et al.; Thyroid Studies Collaboration. Thyroid function within the reference range and the risk of stroke: An individual participant data analysis. J Clin Endocrinol Metab. 2016 Nov; 101(11):4270-82.

31. Auer J, Berent R, Weber T, Lassnig E, Eber B. Thyroid function is associated with the presence and severity of coronary atherosclerosis. Clin Cardiol. 2003;26(12):569-73.

32. Bakker SJ, ter Maaten JC, Popp-Snijders C, Slaets JP, Heine RJ, Gans RO. The relationship between thyrotropin and low density lipoprotein cholesterol is modified by insulin sensitivity in healthy euthyroid subjects. J Clin Endocrinol Metab. 2001;86(6):1206-11.

33. Tatar E, Sezis Demirci M, Kircelli F, Gungor O, Yaprak M, Asci $\mathrm{G}$, et al. The association between thyroid hormones and arterial stiffness in peritoneal dialysis patients. Int Urol Nephrol. 2012;44(2):601-6.

34. Desideri G, Bocale R, Milardi D, Ghiadoni L, Grassi D, Necozione $\mathrm{S}$, et al. Enhanced proatherogenic inflammation after recombinant human TSH administration in patients monitored for thyroid cancer remnant. Clin Endocrinol. 2009;71(3):429-33.

35. Dardano A, Ghiadoni L, Plantinga Y, Caraccio N, Bemi A, Duranti E, et al. Recombinant Human Thyrotropin Reduces EndotheliumDependent Vasodilation in Patients Monitored for Differentiated Thyroid Carcinoma. J Clin Endocrinol Metab. 2006;91(10):4175-78.

36. Yun KH, Jeong MH, Oh SK, Lee EM, Lee J, Rhee SJ, et al. Relationship of thyroid stimulating hormone with coronary atherosclerosis in angina patients. Int J Cardiol. 2007;122(1):56-60.

37. Yang L, Zou J, Zhang M, Xu H, QiW, Gao L, et al.The relationship between thyroid-stimulating hormone within the reference range and coronary artery disease: impact of age. Endocr J. 2013;60(6):773-9.

38. Daswani R, Jayaprakash B, Shetty R, Rau NR. Association of thyroid function with severity of coronary artery disease in euthyroid patients. J Clin Diag Res. 2015;9(6):10-3. 